\title{
A systematic Review Study on the Results of Empowerment-Based Interventions in Diabetic Patients
}

\author{
Mostafa Madmoli ${ }^{1 *}$ \\ Emergency Medical Technician, Dezful University of Medical Sciences, Dezful, Iran*
}

\begin{abstract}
Introduction: Diabetes mellitus is one of the most prevalent diseases caused by metabolic disorders and an important global challenge. Empowerment is a collaborative approach to diabetes care and patient education. In this study, our intention is to systematically review the effects of empowerment interventions in diabetic patients, in order to understand the impact of empowerment on diabetic patients, this study was conducted with the aim of doing this.
\end{abstract}

Materials and Methods: In this systematic review, we used the articles published in the last 30 years regarding the results of empowerment interventions in patients with diabetes. It was conducted in English and Persian by searching articles in search engines, scholarly sites and databases Magiran, Google Scholar, Embase, ResearchGate, Sciencedirect, PubMed, Springer. In the first stage 40 articles were found. Of these, 15 related articles that have been published in the last 30 years have been reviewed.

Results: In this study, 15 papers were reviewed the empowerment approach of diabetic patients increases the level of knowledge, Increasing self-efficacy and improving the quality of life of adolescents, Making positive changes in the overall scale of attitude towards the disease and the patient's independent independence scale, Improve self-esteem scores and self-care and reducing the amount of hemoglobin A1C, Improve overall self-care behaviors, Reducing Glycosylated Hemoglobin and Improving Quality of Life, Blood glucose control (decrease in HbA1c), and so on.

Conclusion: The review of this review confirms the importance of empowerment-based interventions on increased control and self-care in diabetes patients in diabetic patients. Not paying attention to all dimensions of empowerment, not paying attention to the impact of demographic variables on empowerment, failure to follow up programs Lack of training by specialist staff and so on Can be seen by reviewing the results of the studies. Therefore, considering the broad concept of empowerment and as an effective approach to protecting patients with diabetes, its necessary these restrictions will be considered in future research.

Keywords: Empowerment interventions, Diabetic patients, Empowerment approach, Empowerment Program, Diabetes

Address For Correspondence:

Mostafa Madmoli, Emergency Medical Technician, Dezful University of Medical Sciences, Dezful, Iran. E-mail : mostafamadmoli10@yahoo.com

Received: 05-01-2019 Revised: 15-02-2019 Accepted: 05-03-2019 


\section{INTRODUCTION:}

Diabetes mellitus is one of the most prevalent diseases caused by metabolic disorders, a major global challenge. This disease is a chronic disease that results in impairment in the production and function of insulin in the body (1.6). Inappropriate combination (low physical activity and unhealthy foods) has increased the prevalence of diabetes. This disease with multiple complications is not reversible in many cases (7-12).

It is estimated that about 2 percent of the general population of Iran and 7.3 percent of people over 30 have diabetes. Compliance with a program and diet in diabetic patients is one of the pillars of individual diabetes management. Lifestyle behaviors, including nutritional behaviors, play an important role in preventing and managing diabetes. However, compliance with a diabetic diet is one of the most important challenges in controlling diabetes (13-15).

The overall complications of diabetes cause a lot of illnesses. Most studies have shown that patients with diabetes who are less self-healing have more complications $(16,17)$. Depression is one of the most common and debilitating problems in adolescence and among diabetic patients is one of the most common psychiatric disorders $(18,19)$. Depression and occupational stress daily can cause some disorders in people's mental and physical health. Job stress can be considered as a combination of stressful factors and job-related situations most people agree on stressfulness (20-23). High occupational stress is known as a known psychosocial factor in cardiovascular disease (24). Diabetes is one of the most common endocrine complications in people with thalassemia (25). Thalassemia is the most common hereditary anemia in Iran. Thalassemia is a hereditary anemia. The treatment of these patients is continuous blood transfusion. Blood transfusion has complications some of them are related to immunologic complications and some Non-immunological complications such as increased iron loading and the transmission of blood-borne infections including hepatitis B, C and HIV. $(26,27)$.

In general, diabetes can cause many diseases. Scientific evidence suggests that only a small fraction of chronic diseases, such as diabetes, are treated by specialist staff, while most diseases are managed by the individual and his family $(28,29)$. Traditional education seems adequate to meet the needs of patients, however, by recognizing the impact of psychosocial issues and the environment on patients 'behavior, educational techniques were used to change patients' behavior. And the training approach to diabetic patients has changed as well as education based on the theory and research on diabetes and the focus of the capacity building approach to adapt treatment to selfefficacy and empowerment was changed. Empowerment is a collaborative approach to diabetes care and patient education. Which was introduced at the beginning of 1990 by Anderson and his colleagues at the University of Michigan Diabetes and Diabetes Research Center $(29,30)$.

In this study, our intention is to systematically review the effects of empowerment interventions in diabetic patients, in order to understand the impact of empowerment on diabetic patients, this study was conducted with the aim of doing this.

\section{MATERIALS AND METHODS:}

In this systematic review, we used the articles published in the last 30 years regarding the results of empowerment interventions in patients with diabetes. It was conducted in English and Persian by searching articles in search engines, scholarly sites and databases Magiran, Google Scholar, Embase, Researchgate, Sciencedirect, PubMed, Springer. In the first stage 40 articles were found. Of these, 15 related articles that have been published in the last 30 years have been reviewed.

In order to achieve the goal of the study and to improve the accuracy of its study and its comprehension, this integrated overview study was conducted based on the Broome method. The method is done in the form of three steps in the search of texts, data evaluation and data analysis, So, in the search phase, post-retention studies texts are examined in four stages in terms of inclusion criteria. After obtaining the conditions for entry into the study, the content of the study is evaluated and at the end the analysis of the data was done.

The criteria for entry of articles include studies published in Persian and in English, access to their full text was possible, studies conducted on people with diabetes they were published in the last 30 years and 
interventional studies based on the empowerment approach of patients with diabetes outcome criteria included case studies, descriptive and qualitative studies that did not involve educational intervention regarding the empowerment approach in patients with diabetes, unnamed, unannounced, and non-scientific studies as well as articles that lacked the full text of the article were deleted.

To achieve relevant studies, a wide range of keywords including Empowerment interventions, Diabetic patients, Empowerment approach, Empowerment Program, and diabetes was used as a one-to-one search, combined with the method "And" and "OR".

\section{RESULTS:}

The empowerment process in diabetes is achievable through support and training and this action is through preparation, information, multimedia resources, use the right technology and creating skills in diabetes selfmanagement plans is practicable (31). Empowerment is a collaborative approach to diabetes care and patient education that It was introduced by Anderson and his colleagues at the University of Michigan Diabetes and Diabetes Research Center $(32,33)$.

In the empowerment approach, the need for adaptation to the needs of patients and the reflection of their experiences in life with diabetes, with the aim of identifying and enhancing the strengths and making informed choices, it is necessary and specified that Increased awareness about diabetes alone to get started. Maintaining self-management behaviors and long-term control of diabetes is not enough (34).

The results of this study were based on the results of empowerment interventions in people with diabetes that the results of these interventions reduced the mean glycosylated hemoglobin, Improving general selfcare behaviors, and so on. For example, in studies (3540), these interventions raise the level of knowledge, Increasing self-efficacy and improving the quality of life of adolescents, making positive changes in the overall scale of attitude towards the disease and the patient's independent independence scale, Improve self-efficacy scores and taking care of yourself and reducing the amount of hemoglobin A1C, Improve overall self-care behaviors, decrease in mean glycosylated hemoglobin and Improving the quality of life and controlling blood glucose (decreased in HbA1c).

Also, these interventions in other studies enhance the psychosocial self-efficacy of diabetic patients in the post-psychological aspect, promote self-efficacy and reduce $\mathrm{HbA1c}$ increasing the mean score of knowledge, self-efficacy and self-esteem and lowering $\mathrm{HbA1c}$ levels in adolescents, promoting knowledge and confidence in diabetes, increasing the mean score of knowledge and decreasing HbA1c levels. Increasing control over disease and promoting self-care and knowledge, Improvements in the clinical results of HbA1c and LDL and blood glucose lowering, decline in clinical trials (HbA1c and weight and BMI) and improving physical activity, diet and stress and emotion Control, promoting knowledge and understanding about diabetes and reduce cholesterol, weight, blood glucose and BMI, and was improved in quality of life and selfcare behaviors (32), (41-49).

\section{DISCUSSION:}

Diabetes mellitus is one of the most prevalent diseases caused by metabolic disorders, a major global challenge. This disease is a chronic disease that results in impairment in the production and function of insulin in the body (1.6). Traditional education seems adequate to meet the needs of patients, however, by recognizing the impact of psychosocial issues and the environment on patients 'behavior, educational techniques were used to change patients' behavior. And the training approach to diabetic patients has changed as well as education based on the theory and research on diabetes and the focus of the capacity building approach to adapt treatment to self-efficacy and empowerment was changed. Empowerment is a collaborative approach to diabetes care and patient education. Which was introduced at the beginning of 1990 by Anderson and his colleagues at the University of Michigan Diabetes and Diabetes Research Center $(29,30)$.

This study examined 15 research papers, we realized that these studies confirm the importance of empowerment-based interventions to increase control of disease and self-care to promote health in people with diabetes.

According to the results of study (35), there was no significant difference between glycosylated 
hemoglobin and intervention group before and after intervention. And the results showed a significant difference in the level of glycosylated hemoglobin between intervention and control groups after intervention. Also, the mean glycosylated hemoglobin in the intervention group decreased after the implementation of the empowerment plan. It should be said that the implementation of the empowerment program has improved the effectiveness of patients in controlling blood sugar and has been effective in reducing hemoglobin glycosylated levels in type II diabetic patients.

According to the results of the study (36), we can say that Self-care behaviors in total and some subscales such as nutrition and physical activity were significant in intervention group. Self-monitoring, adherence to treatment and foot inspection were significant in the intervention group, but there was no significant relationship between the two groups. Therefore, it can be said that an empowerment training program is needed to improve and maintain some self-care subscales.

According to the results of the study (37), it can be said that the intervention has an effective empowerment model on the quality of life of diabetic adolescents. And is suggested in this study this model will be implemented in other age groups of society and more widely.

In all studied studies, more empowerment on controlling clinical outcomes and promoting self-care behaviors and self-efficacy in diabetic patients. And except for a study that addresses family-centered empowerment and in two studies that used peer support strategies, in other studies, social empowerment was not addressed. While individual empowerment refers to the ability of a person to make decisions and control his or her personal life in social empowerment, people are involved in maximizing the impact and control of determinants of health and quality of life in society (50). The empowerment process is environmentally-social and a social process that is acquired with the participation of others (51), but in most studies, it has not paid much attention to its social dimension.

\section{CONCLUSION:}

The review of this review confirms the importance of empowerment-based interventions on increased control and self-care in diabetes patients in diabetic patients. Not paying attention to all dimensions of empowerment, not paying attention to the impact of demographic variables on empowerment, failure to follow up programs, the lack of a specific theoretical framework of empowerment in some studies, Non-use of appropriate metrics and the lack of training by specialist people can be seen by reviewing the results of studies. Therefore, considering the broad concept of empowerment and as an effective approach to protecting patients with diabetes, these limitations need to be considered in future research.

\section{ACKNOWLEDGMENT:}

The author of this article is grateful to all those who have collaborated with me in this article.

\section{REFERENCES:}

1. Moslemirad M, Madmoli M, Madmoli Y, Niksefat M. Prevalence of type 1 and type 2 diabetes and its related factors in diabetic patients hospitalized in Khatam-ol-Anbia hospital in Shoushtar, 2014-15: A retrospective study. Journal of Research in Medical and Dental Science. 2018;6(3):421-6

2. Madmoli M, Eilami 0, Rezaie K, Aliabad MA, Moslemirad M. Diabetes and the risk of suffering cardiovascular Diseases: A two-year retrospective study. International Journal of Ecosystems and Ecology Science (IJEES). 2018 Jun;8(3): 649-56.

3. Madmoli M Rostami F, Mirsami Yazdi N, Mosavi A, Baraz Sh. Evaluation of Prevalence of Diabetic Foot Ulcer and Its Related Factors in Diabetic Patients Admitted to KHatam-ol-Anbia Hospital in Shoushtar During 2015-2016: A Retrospective Study. International Journal of Ecosystems and Ecology Science (IJEES). 2018 June; 8 (3): 545-52.

4. Rostami F, Madmoli M, Mirsami Yazdi N, Baraz Sh. Evaluation of The Prevalence of Lower Limb Amputation and Its Related Factors in Diabetic Patients Admitted to KHatam-ol-Anbia Hospital in Shoushtar During The 2015-2016: A Retrospective Study. International Journal of Ecosystems and Ecology Science (IJEES). 2018 June; 8 (3): 553-60.

5. Raisifar Z, Afshar Nia A, Madmoli M, Madmoli Y. The Relationship Between Using Insulin and Suffering Alzheimer's Disease in Patients with 
Diabetes: A Two-Year Study. International Journal of Ecosystems and Ecology Science (IJEES). 2018 June; 8 (3): 623-28.

6. Raisifar Z, Afshar Nia A, Maghamesi Moarrefi $\mathrm{H}$, Madmoli M. Evaluation of Gi Bleeding Prevalence and Its Related Factors in Diabetic Patients Hospitalized in KHatam-ol-Anbia Hospital During 2015-16: A Retrospective Study. International Journal of Ecosystems and Ecology Science (IJEES). 2018 June; 8 (3): 609-14.

7. Madmoli M, Kord Z, Bandani A, Sedighi N, Rezaei Shandiz M, Darabiyan P, AfsharNia A. Epidemiological and clinical study of patients with Alzheimer's in Five Cities of Khuzestan Province in 2016-2018. Medical Science, 2019; 23(95), 1-5

8. Mashali H, Toleideh F, Rahmani R, Darabiyan $\mathrm{P}$, Madmoli M. The predictive role of Hyperlipidemia in the incidence of ACS in patients referring to Shahidzadeh Hospital in Behbahan in 2016 -2017. Medical Science, 2018; 22(94), 566-570

9. Madmoli M, Modheji Y, Rafi A, Feyzi R, Darabiyan P, AfsharNia A. Diabetes and its predictive role in the incidence of Alzheimer's disease. Medical Science, 2019; 23(95), 30-34

10. Madmoli M, Fallah bagher shaidaei M, Rohani A, Darabiyan P, Mobarez F. The correlation between alcohol consumption and reducing the age of cancer incidence in patients with this disease. Medical Science, 2019, 23(95), 48-53

11. Madmoli M, Mahmoudi Dehcheshmeh Z, Rafi A, Zahra Kord, Fariba Mobarez, Pouriya Darabiyan. The rate of some complications and risk factors of diabetes in diabetic patients: Study on cases of 3218 diabetic patients. Medical Science, 2019; 23(95), 63-68

12. Mostafa Madmoli, Mehran Yarbig, Negin Sedighi, Pouriya Darabiyan, Fariba Mobarez. Communication between body mass index and the risk of obesity-related cancer: A 5-year study on patients with cancer. Medical Science, 2019; 23(95), 69-74

13. Madmoli M, Madmoli Y, Khodadadi M, Samsamipour M. Some Factors Affecting Quality of Life in Patients with Diabetes: A systematic Review. Annals of Microbiology and Infectious Diseases. 2019; 2(1). 26-30.

14. Madmoli M. Clinical and Laboratory Findingin Children with Leukemia: a Systematic Review. International Journal of Research Studies in Science, Engineering and Technology, vol. 5, no. 10, pp. 1-6, 2018.

15. Madmoli M. Evaluation of Chemotherapy Complications in Patients with Cancer: A systematic Review. International Journal of Research Studies in
Science, Engineering and Technology, vol. 5, no. 12, 2018; 59-64.

16. Madmoli M, Madmoli Y, Khodadadi M, Samsamipour M. Factors Affecting the Level of Glycosylated Hemoglobin in Patients with Diabetes: A Systematic Review. Annals of Microbiology and Infectious Diseases 2(1), 2019; 43-47.

17. Madmoli M, Madmoli Y, Khodadadi M, Samsamipour M. Study of Some Effective Treatments for Accelerating Diabetic Foot Ulcer Healing: A Systematic Review. International Journal of Research Studies in Science, Engineering and Technology. 6(2), 2019; 34-39

18. Lee HJ. Park Ky. Park HS. Self-care activity, Metabolic control, and cardiovascular risk factors in accordance with the levels of depression of clients with type 2 diabetes mellitus. Taehan Kanho Hakhoe Chi 2005; 35: 283-291.

19. Madmoli M, Madmoli Y, Bigdeli Shamloo MB, Etebari A, Mahmoodi Kouhi A, Azami M. The Relationship Between Depression and Religiousness in Female High School Students of Masjed Soleyman in 2015. Journal of Pediatric Nursing. 2017 Jun 15;3(4):15-22.

20. Madmoli Y, Madmoli M, Qashqaei Nezhad N, Bosak S. Prevalence of depression and associated factors in adolescents of Masjed-Soleyman. Iranian Journal of Pediatric Nursing. 2016.

21. Gheisari Z, Beiranvand R, Karimi A, Ghalavandi S, Soleymani A, Madmoli M, Bavarsad AH. Relationship between Occupational Stress and Cardiovascular Risk Factors Determination: A Case-control Study. Journal of Research in Medical and Dental Science. 2018 May 17;6(3):287-93.

22. Madmoli M, Nikpay S. An Investigation of the Relationship between Spiritual Health and Depression, Anxiety, and Stress among Students of Ilam University of Medical Sciences. Journal of Research in Medical and Dental Science. 2018 May 17;6(3):294-300.

23. Adavi A, Hamid N, Attari Y, Madmoli Y, Madmoli M. Study of the Effect of Problem-Solving Skills Training on Creactivity and Assertiveness Among High School Students. Iranian Journal of Nursing Research. 2016 Dec 15;11(5):48-55.

24. Roughani A, Madmoli M, Raisifar Z, Kikhavani S, Yasemi M, Azami M, Sharifi Z. The prevalence of behavioral disorders and its related factors in elementary school children in Ilam City in 2011-2012. Indian Journal of Forensic Medicine \& Toxicology. 2018;12(4):165-9. 
25. Madmoli Y, Akhaghi Dezfuli SM, Beiranvand R, Saberi Pour B, Azami M, Madmoli M. An epidemiological and clinical survey of patients with $\beta$ thalassemia in dezful in 2015. Iranian Journal of Epidemiology. 2017;13(2):145-52.

26. Madmoli Y, Akhaghi Dezfuli SM, Adavi A, Maraaghi E, Heidari Soureshjani R, Madmoli M. The Effect of Orem Self-Care on Mental Health of Patients with Thalassemia Major. Journal of Clinical Nursing and Midwifery. 2018 Jul 1;7(2):108-15.

27. Madmoli M, Madmoli Y, Rahmati P, Adavi A, Yousefi N, Gheisari Z, Abbaszade Aliabad M. Quality of Life and Some Related Factors in Patients with Beta Thalassemia Major in Southwest Iran. Journal of Clientcentered Nursing Care (JCCNC. 2017;3(2).

28. Madmoli M .Quality of Life in Patients with Cancer and Some Factors Affecting it: A Systematic Review. International Journal of Research Studies in Science, Engineering and Technology. 6(1), 2019; 1-7

29. Taheri Z, Khorsandi M, Taheri Z, Ghafari M, Amiri M. Empowerment-Based Interventions in Patients with Diabetes: A Review Study. JRUMS. 2016; 15 (5) : 453-468

30. Tol A, Alhani F, Shojaezadeh D, Sharifirad G. Empowerment approach to promote quality of Life and self-Management among type 2 diabetic patients. J of Health Systems Research 2012; 7(2): 157-68.

31. Funnell M, Anderson R, Arnold M, Barr P, Donnelly M, Johnson P. Empowerment: an idea whose time has come in diabetes education. Diabetes Education 1991; 17(1): 37-41.

32. Adolfsoon E, Strrain B, Smide B, Wikblad K. Type 2 diabetes experiences of two different educational approach-A qualitative study. International Journal of Nursing Studies 2008: 45; 98694.

33. Anderson R, Funnell M, Butler P. Patient empowerment: Results of a randomized controlled trial. Diabetes care 1995; 18: 943-9.

34. Corabian P, Harstall C. Patient diabetes education in the management of adult type 2 diabetes. Health Technol Assessment 2001; 23(1): 1-8.

35. Shahbodaghi Z, Borhani F. The effects of empowerment program on hemoglobin A1C, type 2 diabetes patients. Medical-Surgical Nursing Journal 2012; 1(2): 24-30

36. Shojaeezadeh D, Tol A, Sharifirad G, Alhani F. Effect of education program based on empowerment model in promoting self-care among type 2 diabetic patients in Isfahan. Razi Journal of Medical Sciences 2013; 20(107): 18-31.
37. Heidari M, Alhani F, Kazemnejad A, Moezzi F. The effect of empowerment model on quality of life of Diabetic adolescents. Iran Journal Pediatr 2007; 17(1): 87-94.

38. Emani Z, Reani M, Borhani F, Dortaj E. Effect of empowerment on attitudes towards disease in patients with type 1 diabetes. Journal of Nursing and Midwifery, Kerman 2011; 10(2): 1-8.

39. Ninfa C, Pena-Purcell, May M. Boggess, Natalia Jimenez. An Empowerment-Based Diabetes SelfManagement Education Program for Hispanic/Latinos. The Diabetes Educator 2011; 37(6): 770-9.

40. Zamanzadeh V, Rasoli E, Jabarzadeh F. Effects of intervention-based empowerment on managment psychosocial in diabetic patients. Journal of Nursing and Midwifery 2008; 11: 25-32.

41. Shojaeezadeh D, Tol A, Sharifirad G, Mohajerani M, Alhani F. Education programs based on empowerment model to enhance self-efficacy and its relationship to diabetes control in patients with type 2 diabetes. Iranian Journal of Diabetes and Lipid Disorders 2012; 11(5): 474-82.

42. Heidari M, Alhani F, Kazemnejad A, Tol A, Moezi $F$. Assessing the effect of educational program based on empowerment model on HbA1C among adolescents with type 1 diabetes. Journal of Health Systems Research 2012; 8(7): 1376-84.

43. Adolfsson ET, Walker-Engstrom ML, Smide B, Wikblad K. Patient education in type 2 diabetes-A randomized controlled 1-year follow-up study. Diabetes Research and Clinical Practice 2007; 76: 34150.

44. Pedram Razi S, Sadeghi M, Nikbakht AR, Ebrahimi H, Kazemnejad A. The effect of familycentered empowerment model on knowledge and metabolic control of patients with type 2 diabetes. Journal of Knowledge \& Health 2014; 9(1): 48-54.

45. Adolfsson ET, Starrin B, Smide B, Wikblad K. Type 2 diabetic patients' experiences of two different educational approaches-A qualitative study. International Journal of Nursing Studies 2008; 45: 98694.

46. Carlos K H, William CW, Cindy LK, Wan YF, Winnie HT, Chung KL, et al. Effects of Patient Empowerment Programme (PEP) on clinical outcomes and health service utilization in type 2 diabetes mellitus in primary care: an observational matched cohort study. PLOS ONE 2014; 9(5): 1-10. 
47. Bastiaensa H, Sunaertb P, Wensa J, Sabbec B, Jenkinsd L, Nobelse F, et al. Supporting diabetes selfmanagement in primary care: Pilot-study of a groupbased programme focusing on diet and exercise. primary care diabetes 2009; 3: 103-9.

48. Naik AD, Teal CR, Rodriguez E, Haidet P. Knowing the ABCs: A comparative effectiveness study of two methods of diabetes education. Patient Education and Counseling 2011; 85: 383-9.

49. Tricia S Tang, Martha M Funnell, Morton B Brown, Jacob E Kurlander. Self-management support in "real-world" settings: An empowerment-based intervention. Patient Education and Counseling 2010; 79: 178-84.

50. Pibernik-Okanovic M, Parasek M, PoljicaninFilipovic T, Pavlic-Renar I, Metelko Z. Effects of an empowerment-based psychosocial intervention on quality of life and metabolic control in type 2 diabetic patients. Patient Education and Counseling 2004; 52(2): 193-9.

51. Shearer N, Reed P. Empowerment: Reformulation of a non-Rogerian concept. Nursing Science Quarterly 2004; 17(3): 53-9.

How to cite this Article: Madmoli M. A systematic Review Study on the Results of Empowerment-Based Interventions in Diabetic Patients. Int. Res. Med. Health Sci., 2019; 2(1):1-7.

Source of Support: Nil, Conflict of Interest: None declared. 